Doi. $10.33373 /$ jmb.v4i1.2453

P-ISSN 2656-0631; E-ISSN 2614-5944

Hal. 32-40

Minda Baharu, Volume 4, No 1 September 2020

https://www.journal.unrika.ac.id/index.php/MNDBHRU

\title{
PENGINTEGRASIAN TUGAS PERKEMBANGAN MASA KANAK-KANAK DENGAN CARA MEMPERSIAPAKAN DIRI DALAM MENGHADAPI UJIAN BAGI SANTRIWAN DAN SANTRIWATI TPA/TPQ
}

\section{INTEGRATION OF CHILDHOOD DEVELOPMENT DUTY BY HOW TO PREPARE YOURSELF IN EXAMINATION EXAMS FOR SANTRIWAN AND SANTRIWATI TPA / TPQ}

\author{
Fuaddillah Putra ${ }^{1}$, Wira Solina ${ }^{2,}$ Citra Imelda Usman ${ }^{3}$ \\ 123 (Prodi Bimbingan dan Konseling, STKIP PGRI Sumatera Barat, Indonesia) \\ *3 citraimelda08@gmail.com
}

\begin{abstract}
Abstrak
Kegiatan pengabdian kepada masyarakat ini bertujuan sebagai salah satu upaya agar tecapai dan terciptanya generasi yang mampu meningkatkan motivasi belajar dan pendidikan pada anak serta memberikan pengetahuan kepada anak-anak yaitu santriwan dan santriwati TPA/TPQ terkait meningkatkan persiapan menghadapi ujian dan memberikan tips atau cara dalam mempersiapkan diri dalam menghadapi ujian. Mengingat mitra dari kegiatan ini adalah yang berada pada masa anak-anak, ini berarti bahwa pengetahuan mereka tentang mempersiapkan diri dalam menghadapi ujian masih tergolong rendah. Sebagian anak-anak hanya mengandalkan hapalan untuk ujian. Mereka belum mengerti persiapan apa saja yang harus dilakukan dalam menghadapi ujian seperti: persiapan mental menghadapi ujian, persiapan fisik menghadapi ujian, penyebab kekhawatiran menghadapi ujian, pola dan bentuk soal dalam ujian, kekuatan berdoa, dan lakukan latihan yang tepat. Adapun hasil dari kegiatan ini adalah adanya peningkatan pemahaman dalam mempersiap diri menghadapi ujian. Dengan mempersiapkan diri dalam menghadapi ujian dengan sebaikbaiknya, para anak-anak mempunyai indikasi berpengetahuan yang baik dan prestasi belajar yang tinggi.
\end{abstract}

Kata Kunci ; Mempersiapkan Diri, Menghadapi Ujian

\begin{abstract}
This community service activity aims as an effort to achieve and create a generation that is able to increase motivation to learn and education in children and provide knowledge to children namely students and students of TPA / TPQ related to improving preparation for the exam and providing tips or ways to prepare yourself in the face of an exam. Since the partners of this activity are those who are in childhood, this means that their knowledge of preparing for exams is still low. Some children only rely on memorization for exams. They do not understand what preparation to take in facing exams such as: mental preparation for exams, physical preparation for exams, causes for worrying about exams, patterns and forms of questions in exams, the power of prayer, and doing the right exercises. The result of this activity is an increase in understanding in preparing for the exam. By preparing themselves for exams as well as possible, children have an indication of good knowledge and high learning achievement.
\end{abstract}

Keywords ; Preparing For Yourself in Exam 


\section{PENDAHULUAN}

Mengerjakan tes atau ujian merupakan aktivitas yang sangat dekat dengan masa kanak-kanak, baik ketika sekolah, atau bahkan ketika menjadi santriwan dan santriwati di TPA/TPQ. Mengerjakan tes atau ujian terkadang bukan hanya masalah menghapal materi kemudian mengerjakan soal. Sesungguhnya ketika mengerjakan soal tes atau ujian terjadi banyak proses yang terkait bukan hanya pada saat mengerjakan tes, akan tetapi juga bagimanakah persiapan sebelumnya, reaksi emosional, serta fisik yang bercampur menjadi satu. Dalam mengerjakan soal tentunya tidaklah cukup mengandalkan hapalan yang dimiliki dalam menjawab soal, akan tetapi lebih dari itu, bagaimana persiapan, strategi yang dipilih untuk menyelesaikan soal menjadi kunci sukses tidaknya mengerjakan tes atau ujian.

Menurut Irawadiy, 2009 (Fitria, 2013:96) Persiapan adalah suatu kegiatan yang akan dipersiapkan sebelum melakukan sebuah kegiatan. Tanpa persiapan, kegiatan tidak akan terlaksanakan dengan baik ataupun susah untuk dilaksanakan. Sebaliknya jika persiapan dilakukan dengan sebaik mungkin, maka kegiatan itu akan terlaksana dengan baik. Hasil dari persiapan adalah sebuah kegiatan yang memuaskan. Sedangkan Tarmizi, 2009 (Fitria, 2013:96) menyatakan bahwa persiapan dalam menghadapi ujian dimulai dari persiapan diri, persiapan teknis, persiapan materi ujian, dan pada saat ujian. Persiapan diri adalah persiapan yang dimulai dari dalam diri sendiri, yang meliputi persiapan fisik dan persiapan mental. Persiapan fisik berkaitan dengan persiapan jasmani/fisik dan persiapan kesehatan.

Menurut Sudjana (2019) dalam bukunya Dasar-dasar Proses Belajar Mengajar yaitu persiapan yang dilakukan sebelum menghadapi ujian adalah: a) Mempelajari catatan pelajaran dan membaca buku yang berkaitan dengan materi ujian kemudian membuat ringkasan lengkap dengan menggabungkan catatan pelajaran dan buku yang dibaca. b) Membuat pertanyaan-pertanyaan yang terkait dengan materi ujian. c) Membuat pokok-pokok jawaban dari pertanyaan dibalik halaman pertanyaan tersebut (supaya tidak terlihat ketika membaca pertanyaan). d) Melatih diri untuk menguasai pertanyaan dan 
jawaban yang telah disediakan. e) Meminta guru untuk menjawab pertanyaan yang jawabannya masih dirasa ragu. f) Menetapkan waktu untuk belajar.

Berdasarkan penjelasan di atas dapat disimpulkan bahwa persiapan menghadapi ujian disini adalah hal-hal yang berhubungan dengan persiapan-persiapan yang perlu dilakukan anak-anak sebelum menghadapi ujian pada mata pelajaran tertentu. Kemudian upaya persiapan yang perlu dilakukan anak-anak dalam menghadapi ujian adalah hal-hal yang berhubungan dengan persiapan-persiapan yang perlu dilakukan sebelum menghadapi ujian.

Adapun gambaran umum dari sasaran pengabidan kepada masyarakat ini adalah anak-anak Taman Pendidikan AL-Qur'an yang benar-benar membutuhkan arahan serta ilmu pengetahuan terkait dengan materi persiapan dalam menghadapi ujian, ini untuk mengarahkan anak-anak taman pendidikan Al-Qur'an agar mampu meningkatkan motivasi belajar dalam menghadapi ujian.

Pelaksana kegiatan pengabdian kepada masyarakat ini adalah 3 orang tim dosen STKIP PGRI Sumatera Barat Prodi Bimbingan dan Konseling. Pengabdian masyarakat ini adalah atas inisiatif atau kerjasama dengan TPA Masjid Nurul Khairat. Pengabdian Masyarakat ini bertujuan untuk memberikan pengetahuan kepada anak-anak yaitu santriwan dan santriwati TPA/TPQ terkait meningkatkan persiapan dalam menghadapi ujian dan cara mempersiapkan dirinya, serta memberikan tips atau cara dalam mempersiapkan diri dalam menghadapi ujian.

\section{METODOLOGI}

Kegiatan "Pengintegrasian Tugas Perkembangan Masa Kanak Kanak Dengan Cara Mempersiapakan Diri Dalam Menghadapi Ujian Bagi Santriwan dan Santriwati TPA/TPQ Masjid Nurul Khairat" dilaksanakan pada Bulan Desember 2019 - Januari 2020 di Masjid Nurul Khairat Kota Padang. Bentuk kegiatan merupakan sosialisasi dan penyuluhan. Penyampaian materi sosialisasi dan penyuluhan dilakukan dengan ceramah dan tanya jawab dengan anak-anak yaitu santriwan dan santriwati TPA/TPQ. Materi yang 
disampaikan yaitu persiapan mental menghadapi ujian, persiapan fisik menghadapi ujian, penyebab kekhawatiran menghadapi ujian, pola dan bentuk soal dalam ujian, kekuatan berdoa, dan lakukan latihan yang tepat.

\section{PEMBAHASAN}

Kegiatan pengabdian kepada masyarakat ini, diikuti oleh anak-anak yaitu santriwan dan santriwati TPA/TPQ. Tim dosen tidak hanya mempersiapkan dalam bentuk soal tapi juga mempersiapkan anak-anak yaitu secara fisik dan mental agar tidak perlu takut dalam menghadapi ujian. Menurut Kartini Kartono (Candrawati, 2010:17-19) persiapan yang perlu dipersiapkan anak-anak untuk menghadapi ujian adalah:

a. Persiapan Mental

Salah-satu kesalahan yang banyak dilakukan para pelajar ialah menunda belajar. Akibatnya, kalau waktu ujian sudah dekat, mereka buru-buru mengejar kekurangannya dalam waktu yang singkat. Dalam waktu sangat terbatas mereka mempelajari bahan sangat banyak sekali yang belum pernah disentuh sebelumnya. Belajar secara ini disebut cramming. Hasilnya ialah: kekacauan dalam penguasaan bahan pelajaran dan hasil ujiannya tidak baik. Kalau ada yang berhasil mendapat angka yang baik dari ujian tersebut, itu pada umumnya karena kebetulan; namun penguasaan pengetahuannya tidak mantap. Persiapan itu mulai dilakukan yaitu dengan: 1) Mengulangi dan mempelajari kembali bahan pelajaran selama periode tertentu. Artinya, anak-anak harus mulai belajar sejak permulaan pelajaran itu diberikan 2) Mengulang secara teratur. Anak-anak harus menyediakan waktu setiap hari untuk mengulang pokok-pokok yang penting dari setiap pelajaran 3) Bila waktu ujian sudah dekat anak-anak perlu mengadakan persiapan khusus menjelang ujian dan aturlah waktu untuk persiapan.

b. Kesehatan Badan 
Kesehatan badan termasuk bagian dari persiapan menghadapi ujian. Hal ini jelas, karena kalau kesehatan badan terganggu, maka anak-anak tidak dapat belajar dengan baik dan tidak dapat melaksanakan ujian dengan baik

c. Kepercayaan Pada Diri Sendiri

Kepercayaan pada diri sendiri perlu dikembangkan dalam rangka persiapan menghadapi ujian. Kurang percaya pada diri sendiri dapat mengakibatkan kegugupan, cemas, merasa kurang/tidak yakin pada kemampuan diri atau mengakibatkan anak-anak bertindak terlalu berhati-hati dan takut berbuat sesuatu. Hal semacam ini tentu menghambat dan merugikan diri dalam mengerjakan ujian.

Hal pertama yang tim dosen lakukan adalah melakukan perkenalan untuk menciptakan hubungan baik terhadap anak-anak yaitu santriwan dan santriwati TPA/TPQ yang telah hadir untuk mengikuti kegiatan sosialisasi ini. Perkenalan dilakukan dengan singkat, hangat dan terbuka agar apa yang disampaikan oleh tim bisa diterima dengan baik oleh anak-anak. Selanjutnya menyampaikan maksud dan tujuan dari pelaksanaan pengabdian kepada masyarakat ini, adalah agar para anak-anak memiliki wawasan dan pengetahuan mengenai mempersiapkan diri dalam menghadapi ujian, baik persiapan mental maupun persiapan fisik,

Pada awal pertemuan, tim dosen yang berperan sebagai pengajar mengawali dengan mulai memberikan materi kepada anak-anak. Tim dosen yang memberikan antara lain Fuaddillah Putra, M.Pd., Kons, Wira Solina, M.Pd, dan Citra Imelda Usman, M.Pd., Kons dengan materi: persiapan mental menghadapi ujian, persiapan fisik menghadapi ujian, penyebab kekhawatiran menghadapi ujian, pola dan bentuk soal dalam ujian, serta kekuatan berdoa, Kegiatan pengabdian kepada masyarakat ini dilakukan dengan menggunakan metode ceramah. Tim memberikan materi melalui media visual dan dilanjutkan dengan tanya jawab antara anak-anak dan tim dosen. Mengingat mitra dari kegiatan ini adalah yang berada pada masa anak-anak yaitu santriwan dan santriwati TPA/TPQ, ini berarti bahwa pengetahuan mereka tentang mempersiapkan diri dalam 
menghadapi ujian masih tergolong rendah. Sebagian anak-anak hanya mengandalkan hapalan untuk ujian. Mereka belum mengerti persiapan apa saja yang harus dilakukan dalam menghadapi ujian, pola dan bentuk soal dalam ujian, lalu strategi yang tepat. Ada sebagian kecil yang memang sudah mengerti dan mampu mempersiapkan ujian dengan bijak.

Kegiatan selanjutnya yaitu pelatihan soal-soal dalam menghadapi ujian, terdiri dari dua teknik. Teknik pertama tanya jawab mengenai materi pelajaran yang akan diuji dan teknik tanya jawab mengenai jawaban soal-soal yang diberikan. Suandito (2018:23) menjelaskan bahwa pelaksanaan ujian sekolah ini tentunya memerlukan persiapan. Salah satu bentuk persiapan yang dapat dilakukan antara lain mempersiapkan peserta didik (anak-anak) dalam menghadapi tes. Peserta didik (anak-anak) dipersiapkan dengan cara memberikan materi yang akan diteskan atau materi yang dimungkinkan muncul dalam tes. Dalam kegiatan ini, untuk menambah pemahaman peserta didik akan materi tersebut, disiapkan pula soal yang sesuai dengan materi yang bersangkutan. Pemberian materi yang diikuti dengan soal tersebut dapat dilakukan sebelum pelaksanaan tes.

Selain itu Hasbullah Thabrany, 1994 (Mandar, dkk, 2017:26) mengatakan bahwa mengulang pelajaran dapat ditempuh dengan cara berdiskusi dan membahas soal ujian. Materi yang belum dikuasai dapat didiskusikan dengan teman atau guru mata pelajaran yang bersangkutan. Manfaat membahas soal ujian adalah membantu anak-anak mengenali bentuk-bentuk soal yang akan dihadapi pada saat ujian dan melatih diri untuk menambah wawasan terhadap bentuk soal yang akan muncul dalam ujian. Pembahasan soal ujian yang sulit dapat didiskusikan dengan teman dan guru mata pelajaran yang bersangkutan.

Kegiatan ini berlangsung \pm 2 jam. Ketika kegiatan berlangsung, tim dosen berusaha mencari materi atau pembahasan yang belum dipahami atau sulit dipahami oleh anak-anak. Setelah dilakukan ini, beberapa anak-anak terlihat lebih paham. Hal ini dilihat dari kemampuan anak-anak yang meningkat dibandingkan sebelumnya. 

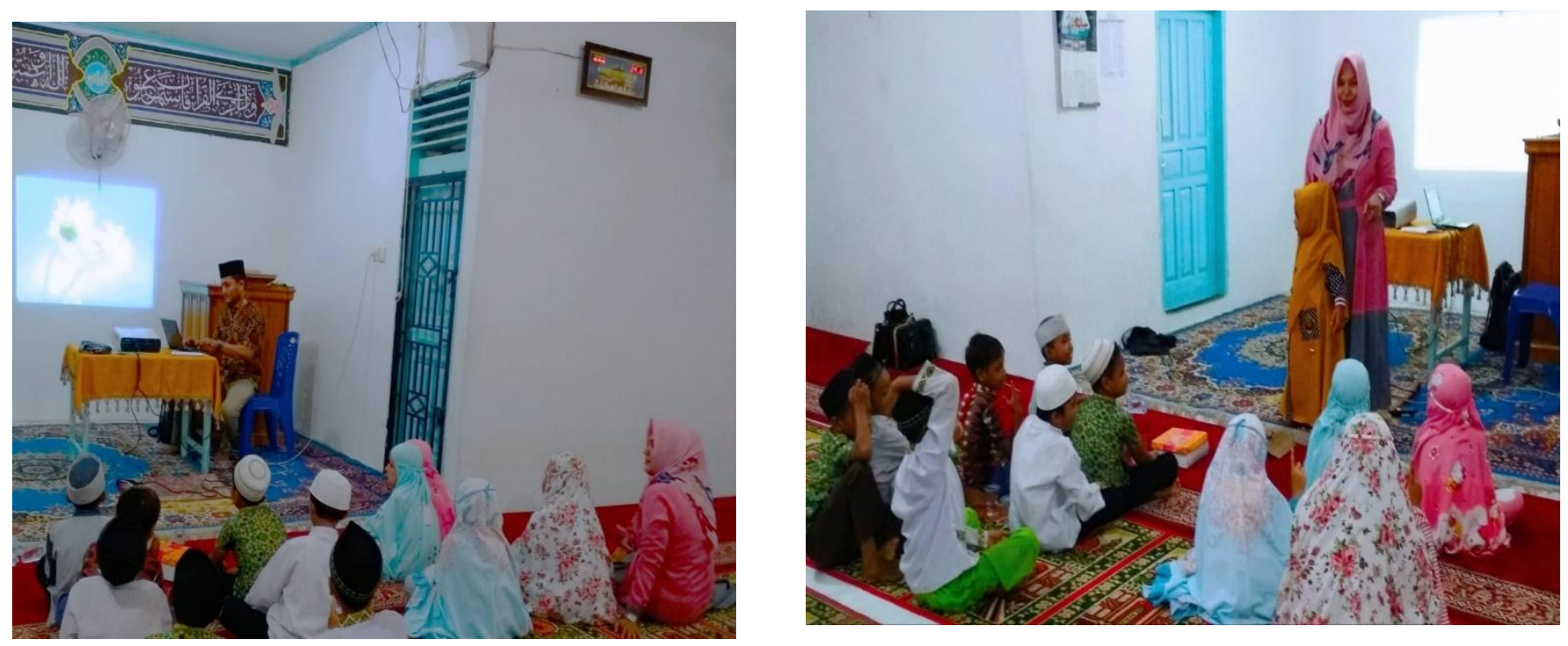

\section{Gambar 1. Suasana Pemberian Materi}

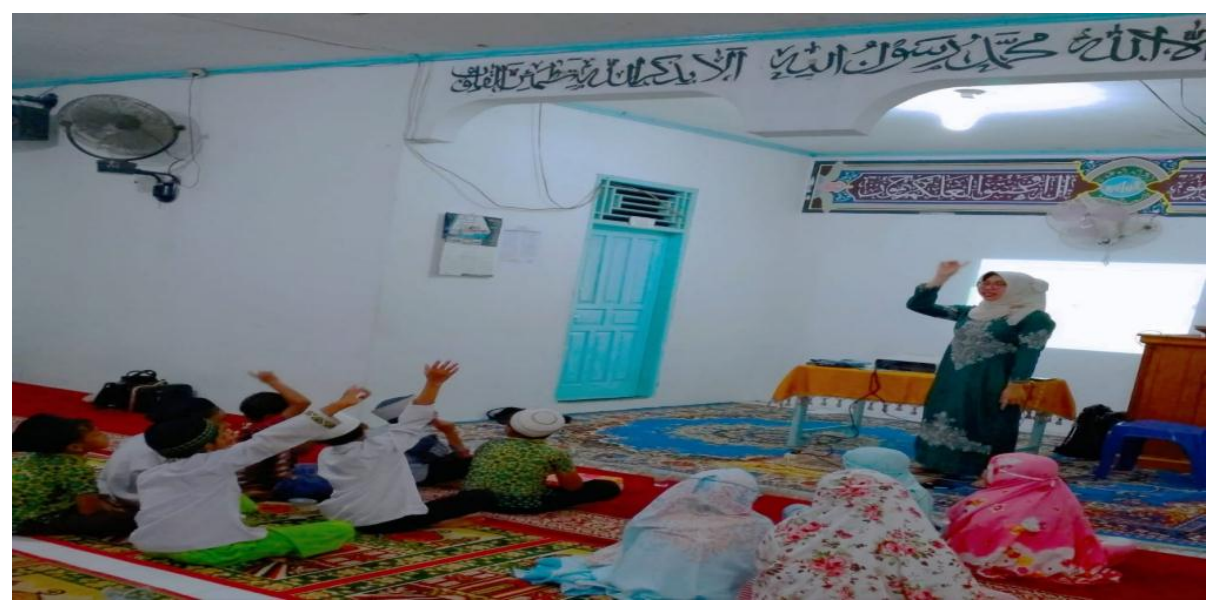

Gambar 2. Suasana Tanya Jawab Mengenai Materi Pelajaran yang Akan Diuji dan Tanya Jawab Mengenai Jawaban Soal-Soal yang Diberikan

\section{KESIMPULAN}

Mempersiapkan diri dalam menghadapi ujian merupakan salah satu faktor yang turut menentukan keefektifan dan keberhasilan pembelajaran, karena anak-anak yaitu 
santriwan dan santriwati TPA/TPQ akan belajar dengan sungguh-sungguh sebelum ujian berlangsung serta memiliki motivasi yang lebih tinggi. Dengan demikian, anak-anak yaitu santriwan dan santriwati TPA/TPQ akan belajar dengan baik apabila mereka paham dengan persiapan yang harus mereka lakukan seperti: persiapan mental menghadapi ujian, persiapan fisik menghadapi ujian, penyebab kekhawatiran menghadapi ujian, pola dan bentuk soal dalam ujian, kekuatan berdoa, dan lakukan latihan yang tepat. Dengan mempersiapkan diri dalam menghadapi ujian dengan sebaik-baiknya, para anak-anak yaitu santriwan dan santriwati TPA/TPQ mempunyai indikasi berpengetahuan yang baik dan prestasi belajar yang tinggi. Hal ini terbukti, setelah dilakukan kegiatan pengabdian kepada masyarakat ini, beberapa anak-anak terlihat lebih paham. Hal ini dilihat dari kemampuan anak-anak yang meningkat dibandingkan sebelumnya.

\section{REFERENSI}

Candrawati, Peronika. 2010. Persiapan Siswa Dalam Menghadapi Ujian Nasional Di Madrasah Aliyah Negeri Kuok Kecamatan Bangkinang Barat Kabupaten Kampar. Skripsi. Universitas Islam Negeri Sultan Syarif Kasim Riau Pekanbaru

Fauziah, Amni, dkk. 2017. Hubungan Antara Motivasi Belajar dengan Minat Belajar Siswa Kelas IV SDN Poris Gaga 05 Kota Tangerang. Jurnal JPSD. Vol 4, No 2, Hal 47-53

Fauziah, dkk. 2017. Upaya Meningkatkan Motivasi Belajar Siswa Melalui Lesson Study di Kelas V SD Negeri Lampagen Aceh Besar. Jurnal Ilmiah Pendidikan Guru Sekolah Dasar. Volume 2 Nomor 1, Hal 30-38.

Fitria, Linda. 2013. Perbedaan Persiapan Siswa yang Hasil Belajar Tinggi dan Rendah dalam Menghadapi Ujian Nasional. Jurnal Konseling dan Pendidikan. Vol. 1 No. 2, hlm. $95-101$

Hamdu, Ghullam dan Agustina, Lisa. 2011 Pengaruh Motivasi Belajar Siswa Terhadap Pestasi Belajar IPA di Sekolah Dasar (Studi Kasus Terhadap Siswa Kelas IV SSDN Tarumanagara Kecamatan Tawang Kota Tasikmalaya). Jurnal Penelitian Pendidikan. Vol. 12 No. 1, Hal 90-96. 
Mandar, Siltia, Syahniar dan Syukur Yarmis. 2017. Kesiapan Siswa yang Ditinggalkan Orangtua dalam Menghadapi Ujian. Jurnal Konselor. Volume 6, No. 1, Hal. 24-28

Riyadi, Slamet dan Mulyapradana, Aria. 2017. Pengaruh Motivasi Kerja Terhadap Kinerja Guru Radhatul Atfal di Kota Pekalongan. Jurnal Litbang. Vol 13, 106-117.

Rahmawati, Rima. 2016. Faktor-Faktor yang Mempengaruhi Motivasi Pada Mata Pelajaran Ekonomi Tahun Ajaran 2015/2016. Jurnal Pendidikan dan Ekonomi. Volume 5, Nomor 4, Halaman 326-336.

Suandito, Billy. 2018. Persiapan Siswa Kelas VI Menghadapi Ujian Sekolah Tingkat SD. Jurnal Abdimas Musi Charitas. Volume 2, No. 1, Hal. 22-26

Sudjana, Nana. 2019. Dasar Dasar Proses Belajar Mengajar. Bandung: Sinar Baru Algensindo 